\title{
Patently transparent
}

$W^{\text {it }}$ ith the proliferation of gene patents and the increasing profusion of biotech patents and licenses with overlapping and competing rights, the ability to interpret and filter intellectual property (IP) has never been more important. Last month's announcement by Australian startup CAMBIA, and its initiative BIOS (Biological Innovation for Open Society), of the creation of an open-access patent database collating IP data from several national patent offices promises to radically improve that process.

In the good old days, looking for a patent involved rifling through card indexes, perusing dog-eared index books and squinting at microfiche. Today, all this has been superseded by the introduction of shiny new webbased interfaces and Boolean search algorithms. You might think that this would have made identifying relevant IP in patent databases a relatively simple task. You'd be wrong.

In reality, searching for a biotech patent has become an inexplicably frustrating and convoluted process. There is no streamlined and universal approach for searching patents filed at the various national and international patent offices. And the three main repositories of English-language filings - the European Patent Office (EPO), the US Patent and Trademark Office (USPTO) and the World Trade Intellectual Property Organisation's Patent Cooperation Treaty —offer databases with online search tools that all work differently and display different results. All require the user to enter numbers, dates and keywords in different formats. Each interface has its own idiosyncrasies, such as failing to recognize certain characters (for instance, apostrophes, slashes or hyphens) or requiring the user to pad a patent number with leading zeros. When you go wrong, online help is unhelpful; trial and error is often the most fruitful approach.
Worst of all, each patent of interest must be downloaded and printed one page at a time- - even though it might be 100 pages long. The explanation is not some technical difficulty, or even a lack of funding or resources. According to the EPO, "this was done as a voluntary restriction at the request of the commercial [patent search firm] operators." In other words, searching and accessing patents has been made difficult purposely so that patent search firms can more readily charge clients for searches.

Fortunately, help is now at hand. CAMBIA's 'Patent Lens' is a freely accessible IP database that contains 2.5 million patents from the USPTO, EPO and PCT, together with a powerful search engine (http://www.bios.net/daisy/bios/patentlens.html). The interface makes possible searches of the full text of patents from all these patent databases. The database can only become more useful as its coverage is extended elsewhere (for instance, to Japan), but its intrinsic value is already clear. It is estimated that underexploitation of technical information (an estimated $80 \%$ of which is published in patent documentation and nowhere else) costs European industry alone \$20 billion each year-simply because the inability to access relevant patent information results in duplication of effort or the creation of products that overlap with prior art.

Patents were conceived as bargains struck between the inventor and the state, not between patent offices and patent search firms. For biotech in particular, researchers, tech transfer offices and company executives need a facile means of establishing the novelty of their offerings and the nature of their competitors' inventions. In this respect, CAMBIA's Patent Lens is a giant leap in the right direction

\section{$\mathrm{BIO} ` 06$ visible from space?}

The $14^{\text {th }}$ Annual International Convention of the US Biotechnology Industry Organization (BIO) was spectacularly big. At this year's meeting, held in Chicago between April 9 and 12, the 176,000-net-squarefoot exhibit hall housed no less than a 1,000-square-foot indoor transgenic cornfield (nearly as much transgenic crop as in the whole of the European Union), an Indy Racing League racecar with accompanying driver, a Ford F-150 Flexible Fuel Vehicle, a Harley-Davidson motorcycle and exhibitors from 50 US states and 62 nations.

The conference has turned into something of an Olympian schmooze endurance test for the 19,479 delegates. For the business forum alone, according to official statistics, 4,260 people representing 1,476 companies participated in 11,018 meetings. Nature Biotechnology is not quite sure how the other 15,219 delegates spent their time.

Viewed through BIO's rose-tinted glasses, biotech is booming in every US state, every Canadian province, each Swiss canton, German Länder, British shire, and French département and city, and in every newly economically progressive nation of the former Eastern bloc or East Asia. There is BioValley, BioVallé, BioVale, BioDale, BioPole, BioPolo, BioCity, BioUrbis and BioVillage. And growing bigger clusters is easy: just take a map, draw a ring round the existing ones and call it a mega-clusterBiocountry, Biobloc or Biocontinent, perhaps, or the Council of European Bioregions.

The question is, with so many clusters vying for biotech, is there enough business to go around? According to a report released at the conference by the nonprofit organizations Battelle Memorial Institute and the State Science \& Technology Institute (SSTI), the answer is certainly “yes." Growing The Nation's Biotech Sector: State Bioscience Initiatives 2006 reckons that in the United States, the 'biotech industry' comprises more than 40,000 companies employing 1.2 million people.

The reality is less impressive. Biotech globally is hardly profitable, and whatever profits and revenues are made are generated by a few hundred large companies, most of which are in the United States. The vast majority of companies are loss-making basket cases, their ability to contribute to a national or regional economy heavily dependent on external finance from investors or government.

The point is not to belittle biotech's economic potential, but simply to be realistic. Biotech companies may aspire to become Amgen and bioregions may aspire to be San Diego or Boston. But those aspirations cannot be achieved by emulation. The next 'Amgen' cannot afford to make all the mistakes Amgen did. And just because the biotech industry grew as a cluster in San Diego, it doesn't mean that it has to do that everywhere from here to eternity.

Thirty years after the foundation of Genentech, venture capital with expertise in biology is not scarce, growing companies from scratch is not a journey into the unknown, our understanding of biology is better, and electronic communication and information exchange are routine and cheap. In short, the need for close geographic networks is diminishing.

Biotech clusters of the near future are going to be virtual. They will be built on shared needs and proximity of interests, not merely on neighborliness. BIO, and similar meetings elsewhere, should be where these networks are initiated, not merely where the biggest clusters are put out for display. 